Research, part of a Special Feature on Resilience Through Multi-scalar Collaboration

\title{
Transition Landscapes and Social Networks: Examining On-Gound Community Resilience and its Implications for Policy Settings in Multiscalar Systems
}

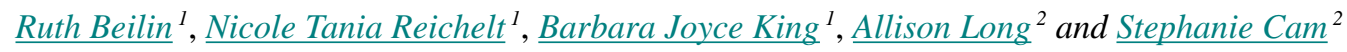

\begin{abstract}
Community based natural resource management groups contribute to landscape scale ecological change through their aggregation of local ecological knowledge. However, the social networks at the heart of such groups remain invisible to decision makers as evidenced in funding cuts and strategic policy documents. Our research is a pilot study of the social networks in two peri-urban landscapes in Victoria, Australia. We describe the social network analysis undertaken with regard to natural resource management issues. The findings are assessed against the qualities of resilience: diversity, modularity, connectivity, and feedback loops. A social network analysis tool is discussed with participants to assess its usefulness on-ground and with agency staff involved in the project. We concluded that the sociograms are useful to the groups, however, the management of the tool itself is complex and calls for agency personnel to facilitate the process. Overall, the project did make visible the networks that contribute to a multiscalar social and ecological resilience in these landscapes, and in this regard, their use is of benefit to policy makers concerned with supporting networks that build social resilience.
\end{abstract}

Key Words: community based; complex systems; Landcare; multiscalar collaboration; resource management; social network analysis; social resilience

\section{INTRODUCTION}

Regional and rural places are dynamic comprising social and ecological landscapes in transition. Leading into the $21 \mathrm{st}$ century, western nations experienced the processes of agricultural transformation (Lobao and Meyer 2001) creating new opportunities and challenges for values associated with agricultural and forestry production and biodiversity conservation. The conditions for landscape change are multiple and include the tangible as well as intangible realities associated with social and ecological aspects of climate and the persistent impacts of markets. As flux follows flux, communities form and reform to create numerous social networks across multiple scales internal and external to their regions. We examined how the participants in a community based natural resource management program (CBNRM), in the form of an Australian initiative Landcare (LC), engaged with landscape scale social and ecological change. Historically, LC in Australia has played a significant role in private land stewardship and the development of CBNRM best practices (Campbell 1994, Alexander 1995, Curtis et al. 2008). In the 21 st century, funding of CBNRM programs is being tied to on-ground outcomes that clearly demonstrate environmental improvement, for example, countering soil loss, tunnel erosion, improving riparian zones, fencing out revegetation and remnant indigenous flora, and similar indicators of visible landscape change. Significantly, the social drivers and the social practices that contribute to the accretion of local ecological knowledge (LEK) and consequent landscape change are rarely recognized by natural resource management (NRM) central funders as outcomes of the CBNRM process. Their invisibility in the landscape is in part a denial of what Samuels (1979) and others (Relph 1976, Meinig 1979, Williams 1990) would describe as the biographical reality of the social construction of landscape that also reflects its physical attributes (Stedman 2003).

As researchers, we have all had a significant involvement in Landcare at various points in its history and have an empirical and anecdotal awareness of the potent social underbelly supporting these ecological changes in the regional landscape. We, and others, argue that unless the social drivers of landscape and particularly those associated with its ecological change are recognized by funding bodies, there is a distinct possibility that such programs will be under or unfunded in the current vogue for auditable and production-centric resource investment (Simpson and Clifton 2010, Robins and Kanowski 2011). Research by Bodin et al. (2006:1) affirmed that "social networks [are] real observable phenomena" and because LC is built on formal and informal networks, we turned to social network analysis as a possible way of demonstrating the existence and importance of this apparently hidden underbelly. We initiated a pilot study, a two-site case study, to explore the viability of the ideas before any larger roll out could occur.

Historically, Yamaguchi's (1994) mathematical modeling of social network analysis (SNA) attributes reflected the importance of social action in the diffusion of information within social networks. This quantitative 'proving' of SNA as a way of modeling and measuring social interaction reinforces subsequent confidence in structural mapping of networks and 
biophysical scientists' confidence in this tool. Such interest reflects the application of SNA across multiple disciplines, including ecology, psychology, organizational management (see for example, Stein et al. 2011), and creativity and innovation in industrial design (Simon and Tellier 2011). SNA appears to offer a platform for interaction with social science qualitative theorists that is useful for those seeking ways to describe the interaction between social and ecological systems and quantitative and qualitative methods. As in Crona and Bodin's (2010) fisher study, we combined quantitative and qualitative data collection and the use of SNA as a way of mapping local LC networks. Further, Marin and Berkes (2010) network approach has particular resonance with the kind of social and ecological platform building observed in LC activities that are both very local and then transformed into regional and even national practices. It is the networking of the networks that offers opportunities for intra and mutiscalar collaboration. LC operates from group to regional network, to statewide facilitator structures, and across scales to engage with the National Landcare Facilitator Project (Landcare Australia 2012).

Bodin et al. (2006) considered network structure with regard to trust, social memory, and the learning associated with adaptive management within their study's actor relationships. They indicated that the structural characteristics of such networks articulated the patterns of connectivity between actors, and these influenced NRM outcomes (Bodin and Crona 2009). Because it originated in landscape ecology, connectivity relates to the ability of animals to traverse vegetation patches and how such movement is enabled or impeded by the spatial configuration of landscape elements (Burel and Baudry 2003). This is distinct from connectedness, which refers to the proximity of structural elements, i.e., patches of the same vegetation type located adjacent to one another to provide structural continuity of habitat, but not necessarily connectivity. In extending this concept of landscape connectivity to the social networks in a landscape, we considered the importance of structural function. For example, participatory social network structures could be expected to demonstrate dense and two-way internal communication flows and qualities of social coherence such as trust, i.e., who do you trust for information. The structure and function of these networks would be dependent to some extent on the resources, social and economic capital, and the organizational norms and procedures that supported them in related decision making at multiple scales. Although high connectivity in an ecological landscape is not inherently positive (Taylor et al. 2006), in a social network, having strong connections is more central to establish an environment of trust, reciprocity, and dependability (Adger 2003). However, the network does not need to function as a highly connected system at all times to remain functional. These networks can also include other sociological insights, for example, concerning power relations between fisher folk (Crona and Bodin 2010), the international food sovereignty movement, Via Campesina, involving thousands of smallholder farmers (Altieri 2012), and social movements in urban park systems (Ernstson et al. 2008).

Our pilot study emphasized the visual display of the SNA tool and the incorporation of qualitative processes. The ability to use the tool for quantitative analysis in future situations was important in its selection among the participating government agencies. In contrast to the Marin and Berkes (2010) and Crona and Bodin (2010) papers, in which qualitative data was integrated into the quantitative data sets, we used the visual display of the SNA maps to interrogate local understanding of group coherence and capacity.

Community based natural resource management government agency personnel and the social researchers in this project were attracted to the visual display associated with SNA mapping. We hypothesized that it might be possible to make aspects of the social connectivity visible within the LC groups. Further, we would include group feedback sessions and individual interviews to find out whether such maps made sense, that is, provided a convincing narrative about their local LC group. Because LC is inherently action oriented, it was central to our thinking that the SNA tool would only be useful to the groups if it empowered them, for example, in assessing their inherent and active social capacity, reflecting the quality of their on-ground organizational structure and function. More practically, we asked if SNA could provide the kind of evidence conservation funding agencies, made up largely of biophysical scientists, require in approving project support intended to deliberately strengthen the social systems underpinning ecological change in the landscape, even if such on-ground collaborative management potentially challenges, as Ernstson (2011:257) suggests "top down management arrangements."

Consequently, the pilot study was guided by two overarching research questions: (1) what does institutional capacity building look like in the context of CBNRM and (2) if made visible, what does knowing how social connectivity operates in these complex transition landscapes contribute to the actions of landscape stewards, managers, and agency policy makers? As for the underlying theoretical question "can SNA demonstrate social resilience" it depends on how social resilience is defined and the qualities associated with that definition, which we discuss in more detail.

\section{BACKGROUND}

\section{The community based natural resource management and Landcare paradox}

In 2008-2009, approximately $40 \%$ of all landholders in Victoria were involved in LC. This is a level of engagement that far exceeds the 10 to $15 \%$ associated with production- 
centric agricultural extension programs (State of Victoria 2010). Although the actual farm productivity of the landscape is declining in gross domestic product (GDP) terms relative to the number of farms, the increase in CBNRM members active on-ground suggests many of the burgeoning numbers of peri-urban migrants join local Landcare groups and augment what would otherwise be a decline in rural farming population. Recent policy decisions diminished total funds allocated but continue to support LC until at least 2013 when the current five-year program runs out. Uncertainties surrounding funding allocation continue to threaten Landcare at a national level as a provider of CBNRM services. Federal government decisions to decrease funding to local LC network coordinators (Curtis and Sample 2010) and the downsizing of the Caring for Our Country program, previously National Heritage Trust, has been criticized for the overall undermining of regionally based NRM. This has included the marginalization and disenfranchisement of LC from policy networks and strategic decision making processes (Robins and Kanowski 2011).

We hypothesize that a significant reason for the decline in government funding for CBNRM is that although LEK is recognized as invaluable among LC supporters, it is officially devalued, as in the State of the Environment Report (SoE; State of Victoria 2008) because of the imperative to measure funding of CBNRM against visible improvement in overall environmental outcomes. The SoE in 2008 indicts the continuing land degradation associated with environmental decline across most benchmarks in the state. The temporal scale mismatch creates a lag phase between activities in CBNRM and improved environmental conditions. As well, this SoE does not comment on the economic drivers that act against environmental change in the same landscapes. The implication is that community LC and similar CBNRM groups have 'failed.' The paradox for policy is that $\mathrm{LC}$, in particular, and CBNRM networks, in general, are regularly, positively referred to in regional and at national level policy papers as creating and housing the social networks associated with social capital, including the community resilience that is desired and desirable in the countryside (Australian Government 2012, The State of Victoria 2012).

Beilin and Reichelt (2010) conclude in their extensive literature review on LC and social resilience that the very nature of LCs evolution has been at a grassroots and community scale and the quality of these networks as sources of LEK, as an incubator for such learning, is part of the culture developed over 25 years. This recognition of LEK or the social networks that support LC learning remains largely undervalued by policy makers and scientists. In contrast, social scientists have long noted its importance in rural and regional society (Lawrence 1987, 1995, Ewing 1995, Beilin 1999, Carr 2002). Researchers have indicated that participation is at the core of engagement in LC for social and ecological activities.
However, counting has been the only form of monitoring such participation and measures only outputs at best: the number of members, the number of trees, the number of fence kilometers along riparian zones (Curtis et al. 2008, 2010). It does not measure the community building processes that the government commends with phrases like "building community resilience." The systems of organization, such as the internal networks within the LC groups, the movement of knowledge, the experience of NRM learning, are not visible in this counting process and therefore remain largely unreported. The paradox for LC and CBNRM, therefore, is that despite previously acknowledged successes in creating an LEK base and despite the recognition that community resilience depends on improving LEK, CBNRM programs like $\mathrm{LC}$ are being underfunded, and thus their value in contributing to landscape scale change is compromised.

\section{The social resilience framing}

This pilot study evolved in 2009 and involved working with 12 LC facilitators and agency staff in a 2-day workshop on social resilience. We began by hypothesizing the meaning of social resilience in LC terms, conceptualizing LC activities within a CBNRM system. We used Walker and Salt's (2006) description of the qualities of resilience to define social and ecological values. Four categories: diversity, modularity, feedback, and redundancy are summarized from that workshop.

\section{Diversity}

Diversity provides the source of options, "natural landscapes consist of mosaics of vegetation patches" (Harris 2007:200), and these we typified as literally the landscape mosaic and the social mosaic. In ecological terms, this could be the plant species palette available for revegetation in a region. In social terms, it includes the plethora of skills and ideas that communities, networks, and groups contain and can draw on for innovation and adaptation. Prell et al. (2011:95) reflect on the importance of "“diversity' in considering 'wide representation' of stakeholders" and in assessing "diversity based on social networks, i.e., diverse positions within a wider network structure."

\section{Modularity}

Modularity as described by Janssen and Osnas (2005) is a system made up of a collection of modules or functional components that change and evolve to some extent in an autonomous manner. Modules can be components of a subsystem or on another scale, subsystems can function as modules within a larger complex social-ecological system. For example, local social networks, regional economic systems, and bioregional water catchments can all function as part of a national NRM system. High modularity is described as a loose structure of linked modules in which change in one module is unlikely to have a severe impact on other modules, or at least change is likely to move slowly throughout the whole system 
(Janssen and Osnas 2005). If components are linked in such a way as to function with high dependency on each other, displayed as a dense set of relations across a system, i.e., low modularity, then change through shocks/disturbance is likely to travel through the system very quickly, potentially causing system collapse. Another feature of high modularity is diversity in experience and responses, so that social learning can occur within and across modules. High modularity suggests that each component or network node may have unique characteristics that may be of benefit for the resilience of the whole system. An illustration of high modularity in a social context is Andersson and Ostrom's (2008) polycentric governance systems associated with the management of the global commons. In their model, natural resource governance is not concentrated at a central node as a distribution point for bureaucratic and political knowledge and power across the system, rather governance capacity, power, and processes are located at various sites and scales across the whole system. Relations between sites of governance may be strategic or emerge through circumstantial necessity.

\section{Feedback}

Tightness of feedback(s) is a part of modularity in that the negative or positive feedback loop(s) affect outcomes to and in the module (Johnson 2001). Feedback informs how quickly and strongly the consequences of change in one part of the system will impact the other parts. Harris (2007) points to global markets as an example of the impact feedback has within, in this case, the economic system of a nation or a region. Further, as Folke (2006) notes, feedback will be at multiple scales, which allow systems to self-organize to some degree. Landcare Forums are an example of feedback loops that celebrate innovation and provide a venue for information and knowledge exchange. These occur at both state and national levels each year. Ideas about optimal ecological restoration practices, for example, are disseminated and transformed by local adaptation to species and soil types. These local responses also affect the techniques used to achieve broader and mutual aims of restoration within and across production landscapes.

\section{Redundancy}

Redundancy generally refers to function and is a good thing in SES terms because redundancy of one species, object, or group, as in its loss to the overall system, doesn't jeopardize the whole system. A system is likely to be more robust if high levels of redundancy exist and can be actively built into social ecological systems. Ostrom (1999) indicates that institutional redundancy increases response diversity and flexibility of a system (Walker and Salt 2006). Redundancy is apparent in the LC group experience. Each group, and often subcommittees within, develops internal functions that serve particular purposes associated with strategic values such as seed-banking or sustainable farm practices. This translates into a multifunctional CBNRM network for landscape management that can keep operating even if one or more national or local projects end.

As researchers and cofacilitators working with agency personnel, we understood that by locating these four qualities of resilience within the experience of $\mathrm{LC}$, we were all engaged in defining on-ground the meaning of social resilience. These government agency coordinators were affirming that, as Folke (2006:260) says, "resilience [is] an approach or way of thinking." These workshops were central to legitimating the experiences of these regional LC coordinators, providing a space to assemble their reflections and experiences of LC and CBNRM. The resilience discourse provides a framework to move past the "pathology of NRM" that Holling and Meffe, (1996) refer to, and to move toward recognition of a system in which resource and landscape management includes social and ecological subsystems. The idea of using the SNA tool arose during these workshops because the multiscalar collaborations within and across LC networks were discussed over and over as central to the program's latent and recognized successes in promoting LEK and its practices.

\section{METHODS}

\section{Study site and data collection}

The SNA study involved two peri-urban LC groups. LC Group A (LGA) was located in northeast Victoria about four hours from Melbourne, and LC Group B (LGB) was situated within an hour of metropolitan Melbourne and was connected to two catchment management authorities (Fig. 1). Collection of data involved four stages: (1) project scoping in consultation with Victorian government agency representatives; (2) structured 20-minute telephone interviews with 35 LC group members to construct the network maps using modeling software, Pajek (De Nooy et al. 2005); (3) presentation of the SNA network maps to the Landcare groups in a sense making process; and (4) structured telephone interviews with 14 randomly selected LC participants from these groups, to provide feedback on their experiences with the SNA tool and process. LC group recruitment commenced with a focus group session inviting eight local LC groups to trial an SNA activity. LGA was recruited from this focus group. Department of Sustainability and Environment (DSE) personnel selected LGB based on the research criteria, i.e., peri-urban location, demographic change, and a history of agricultural land use. Pilot participants were recruited through email distribution lists that were coordinated by LC representatives and through attendance at LC meetings. The random purposive samples for both LGA and LGB included most of the office bearers ensuring network activity involved key membership roles. The office bearers represented various interests within their local communities and frequently liaised with the local government institutions. Most had been involved in their groups and communities for many years. Their level of engagement in their communities and their individual and collective NRM knowledge meant 
they were well positioned and motivated to contribute to the study. However, the mapped networks are incomplete because we mapped only the NRM respondents for each group and their named contacts, and not all members of each group were respondents. With the data available, we combined the personal networks to create a community-based NRM network for each of the pilot LC groups. It is not therefore valid to generalize the SNA pilot results to the wider Victorian LC community. However, it was possible to construct a picture of the social networking occurring in the two pilot LC groups.

Fig. 1. High priority natural resource management issues for Landcare Group A respondents.

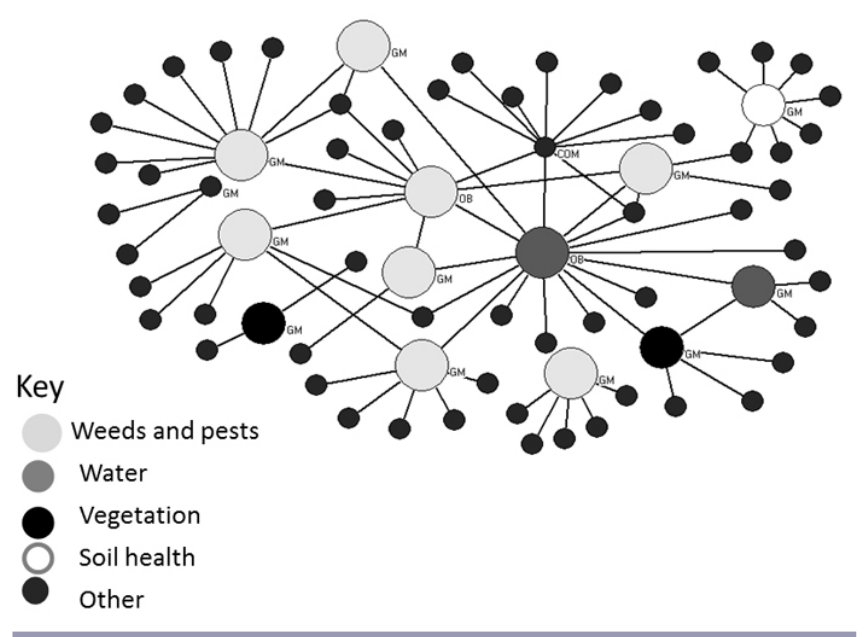

The SNA design used in this study was based on a one-mode network in which the network actors were all LC members. The relationship of interest was focused on the interactions between the LC actors and their named contacts. We analyzed the two pilot LC networks in relation to their degrees if connectedness and clustering patterns to see how insightful these measures were in indicating CBNRM network functionality at the community group level and in association with ideas of social resilience. The most connected nodes were indicated by their degree frequency and were located centrally in the network sociograms.

For LC Group A, 15 respondents (ego) were interviewed and generated a combined network, including respondents and their alters, of 73 nodes. For LC Group B, 20 respondents were interviewed and generated a combined network of respondents and their alters of 102 nodes. The network boundaries were therefore defined by the nodes representing LC actors, primary respondents or egos, and the people they nominated as their NRM contacts, alters. Each amalgamated network was analyzed separately. The combined number of respondents (35) provide an appropriately qualified sample on which to base the analysis particularly because interviewing all members of both LC groups and their alters was outside the scope of this pilot study.

The first interview had two purposes, first, to gather contact data regarding 'who talks to whom' about NRM issues, and second, to gather qualitative data in relation to what NRM issues were priorities for each respondent. During the interviews the respondents named the NRM issue(s) that were of highest priority for them individually. This generated a list of nine NRM issues for LGA, of which weed management and control of rabbits were the highest priority. For LGB, 10 NRM issues were named, of which weed control was the significant priority. LGA and LGB generated different lists of priority issues reflecting the local nature of NRM concerns. During the interviews, respondents were also asked to describe the nature of their relationship with each alter, for example, whether alters were friends, family, neighbors, colleagues, or NRM professionals. In some instances respondents referred to organizations, such as universities or government organizations rather than individuals. For the purpose of mapping the network structure of each LC group and understanding the complexity of NRM information sharing, the organizations were recognized as nodes in addition to individual alters. This allowed for different network clusters to be identified, including those based around personal/social networks, i.e., family and friends, place-based networks, i.e., neighbors and other locals, activity-based networks, i.e., colleagues and recreational contacts, as well as professional/ knowledge-based networks, i.e., government organizations and educational institutions, therefore capturing some intranetwork diversity.

As a pilot study, the methodology outlined was exploratory and intended to inform the implementation of SNA more broadly to characterize the connectivity of other LC groups in Australia. The learning from the methodology was therefore very important. During feedback with LC groups in which the network sociograms were shown and discussed as part of sense-making processes with each group, ethical issues relating to maintaining confidentiality limited the extent to which the communities could explore some of the implications of their networks (Prell et al. 2011). However, the visual opportunity provided by the SNA sociograms to consider relational connectivity within LC groups also presented opportunities for significant learning and insight.

\section{RESULTS}

The empirical findings from the structured interviews and the sociogram group discussion sessions indicate attributes of social resilience as we have defined it.

\section{High diversity}

Diversity is about having a range of interests and options. Referring to Figures 1 and 2, both LC groups nominated a range of issues that they were concerned with and felt reflected 
the complexity of local natural resource management and specific interests of the LC membership. Although the most common NRM priority for pilot participants was the management of pest plants and animals, a variety of other high priority NRM concerns were nominated: bushfire management, soil health, proposed quarry site, riparian vegetation, rain patterns, water issues, biolinks, landscape planning, future LC funding and sustainable land use. Clearly, the LC community is not a single-issue network. Furthermore, the SNA maps captured diverse clusters of NRM-issue based contacts of LC pilot participants. The social structure of both LC NRM communication networks displayed in Figures 3 and 4 , is nonhierarchical with no one person or set of people formally designated as NRM knowledge brokers, which is consistent with LC participatory principle.

Fig. 2. High priority natural resource management issues for Landcare Group B respondents.

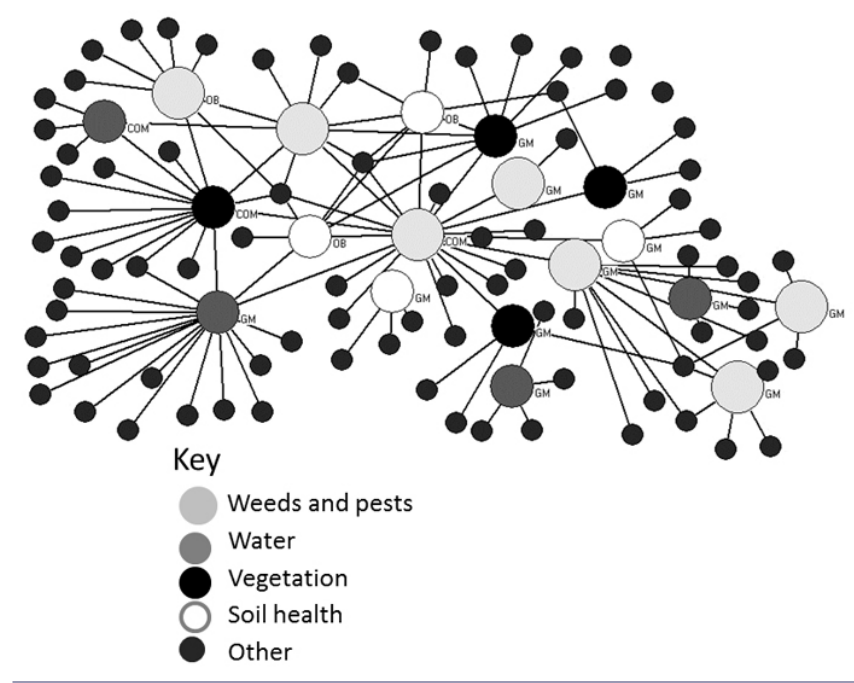

Participants displayed unique sets of contacts for communicating and gathering information about their priority NRM issue, i.e., participants did not generally mention the same people (represented as black dots in Figs. 3, 4). LGA and LGB members identified multiple nodes of communication and sources of information, mentioning individuals, specific family members and nonlocal friends, neighbors/local friends, work, state agencies, local shire, expertise, business/service providers, other LC groups, and catchment management authorities. These connections therefore provide opportunities for knowledge sharing at multiple governance scales, through formal and informal communication with government agencies, local government, and catchment authorities, as well as at a local/community scale. During the feedback process with network participants of LGB, the visual display of the group's connectivity to the wider community was recognized:
Fig. 3. Landcare Group A issue-based social network and respondent's role in Landcare.

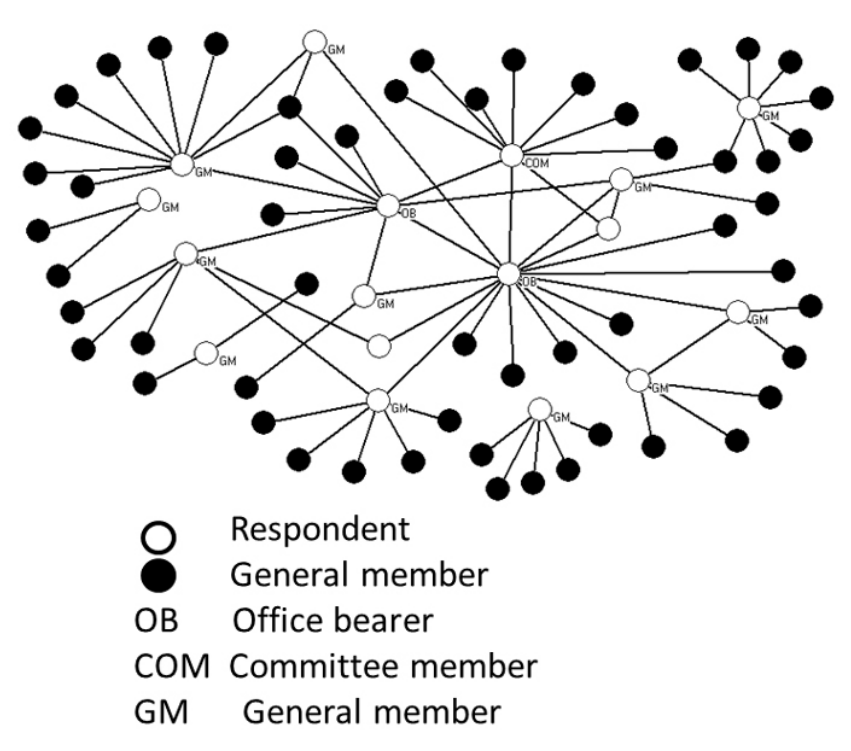

Fig. 4. Landcare Group B issue-based social network and respondent's role in Landcare.

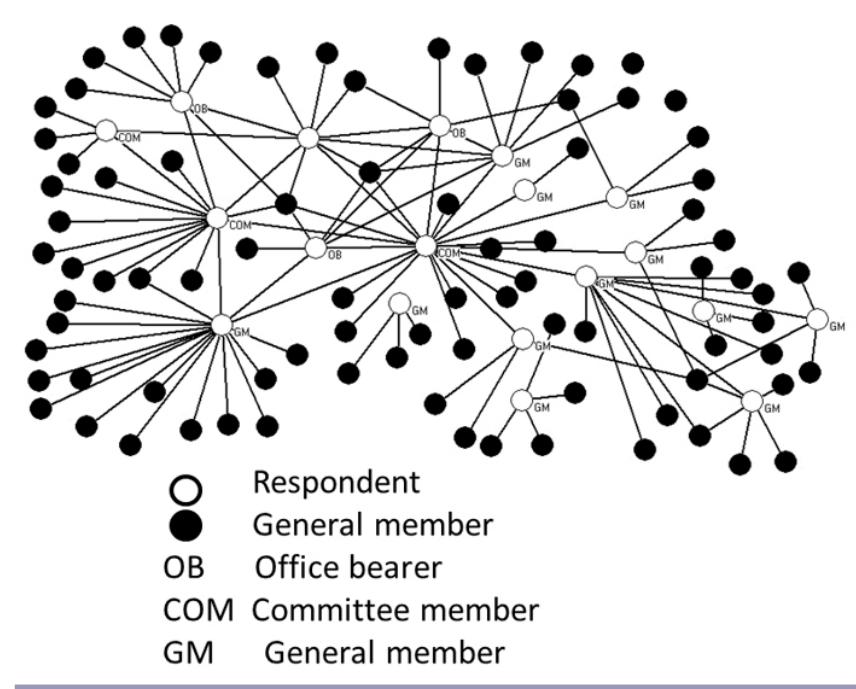

The different structures and interconnected nature of people's networks was interesting because it showed that [LGB] was not an isolated community (SNA participant [24], follow-up interview 2009).

This reflection, from LGB, positions LC as operating both at a local community group, but also as a recognized and valued conduit to other scales. The unique sets of NRM communication networks among the sampled LC members 
was explained by one LGA member during a group feedback session, emphasizing that landholders need individual NRM information networks these days because the generalist knowledge that was previously held by government agencies is no longer available. Others pointed to the loss of local agricultural extension services and said that in general, public access to NRM knowledge is limited. As well, a contributing factor to finding distinct sets of NRM contacts was the different NRM priorities people had within the pilot groups. An additional question was added to the SNA telephone interviews for LCB, exploring whether people's contacts for the priority issue would change if they had nominated their second priority NRM issue. There were instances in which LC members said that they did contact a different set of people because of the issue.

\section{High modularity}

Modularity was high in both aggregated LC group networks because the overall social structure is only loosely connected throughout the sampled LC membership with clustering around different NRM communication networks (Fig. 5-10). Overall, the range of NRM priorities represents a diversity of interests and knowledge bases across each group. Issues of vegetation and water, including bushfires, would appear to be specific NRM priorities across both groups in that people have individualized, personal networks to talk about such issues without necessarily connecting to other LC members, creating a modular network structure.

Fig. 5. Landcare Group A interest clusters - vegetation.

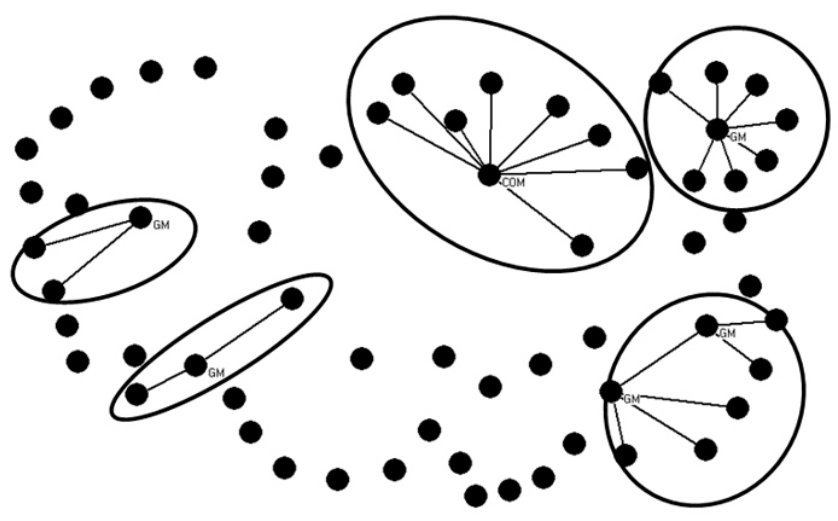

This form of modularity means that if one communication cluster fails, other NRM communications are likely to be unaffected or minimally impacted and will continue functioning as active networks. The exception to this tendency was weed and pest issues, particularly in LCB, because they were a common priority for a number of SNA pilot participants thereby connecting most members into a cohesive group.
Fig. 6. Landcare Group B interest clusters - vegetation.

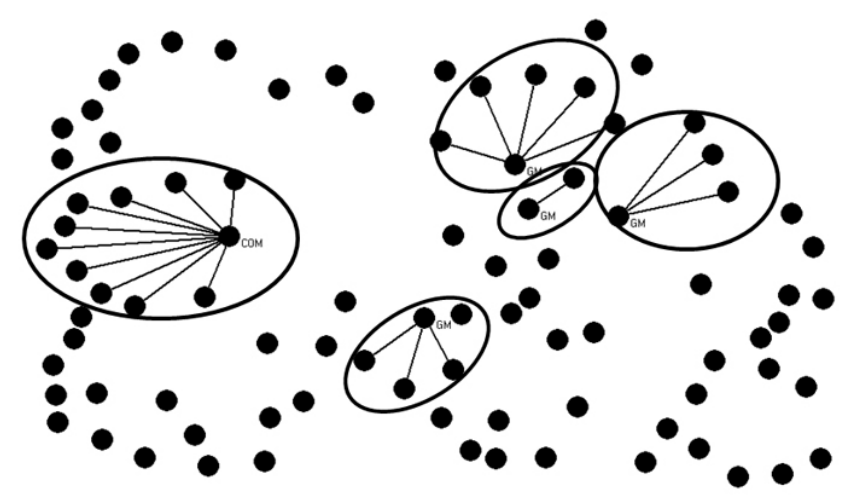

Fig. 7. Landcare Group A interest clusters - water and bushfire.

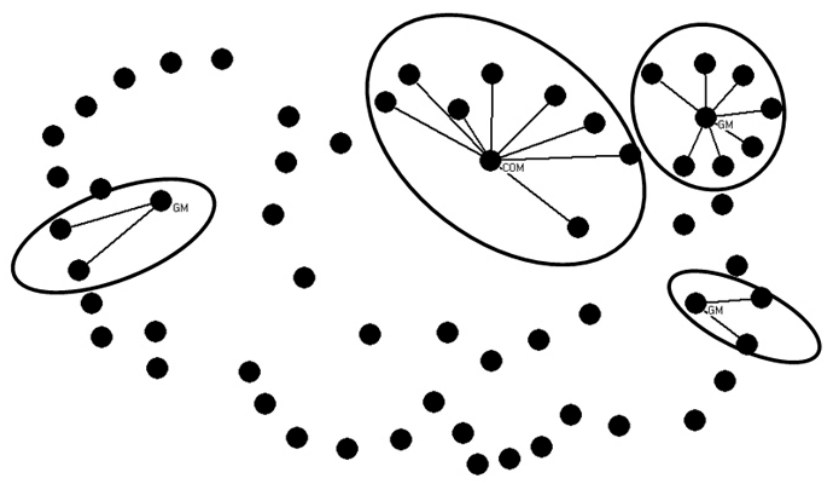

Fig. 8. Landcare Group B (LGB) interest clusters - water and bushfire.

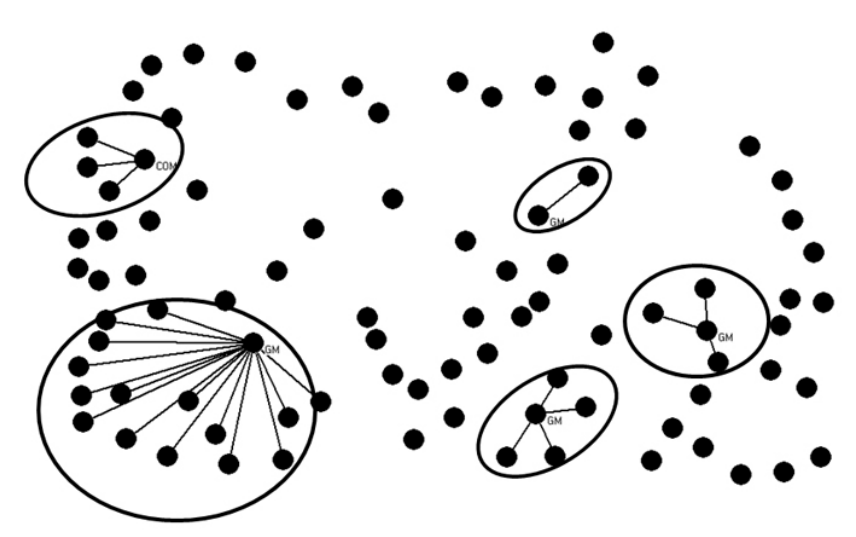


Fig. 9. Landcare Group A interest clusters - weeds and pest animals.

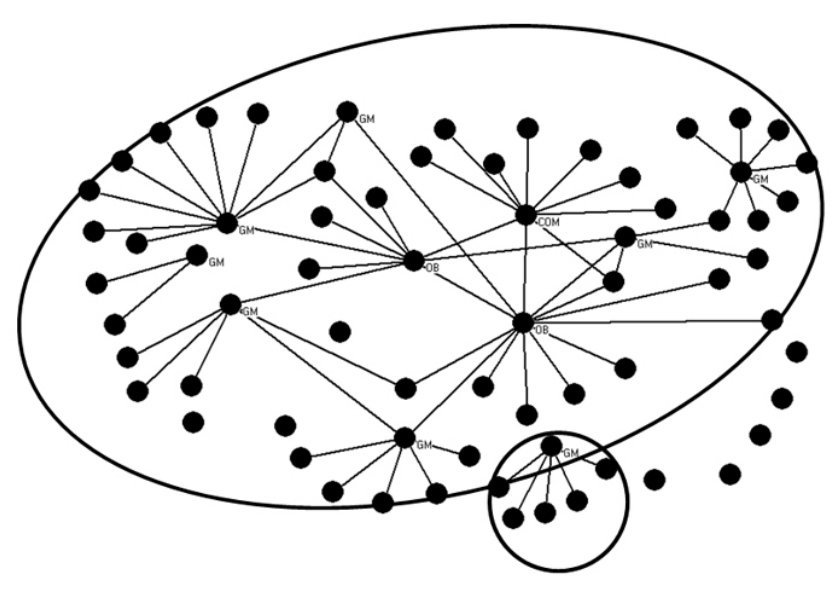

Fig. 10. Landcare Group B interest clusters - weeds and pest animals.

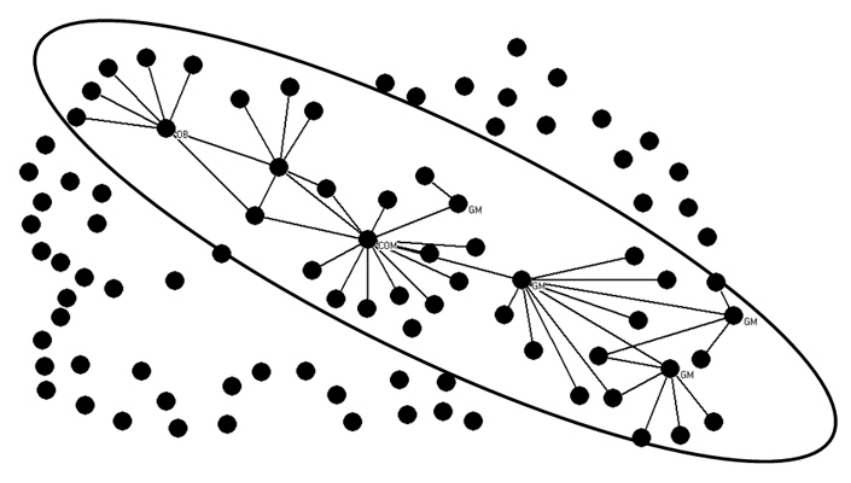

The distinct clustering around NRM prioritized issues and the communication of information of interest within these clusters, as illustrated in Figures 5-10, was also affirmed by the presence of specialist project committees within the groups, as captured in feedback sessions. Examples of this are the weed and animal pest eradication, biolink, and riparian rehabilitation subgroups. These are clear examples of high modularity for both LC groups. These administration, project, and communication-based modules appear to develop specific knowledge and processes independently of other LC group activities, reinforcing our insight that there are diverse ways for LC members to relate and respond to social-ecological issues.

\section{Negative and positive feedback loops}

Feedback loops are closely related to modularity and can create positive or negative responses to the system. They are the rate at which the consequences of change have an impact on other parts of the network. An example of a positive 'tight' feedback loop described by LGB is their annual, inclusive LC Christmas gathering. Its organization as a community-wide outreach event encourages people to continue their membership as participants in an active landscape-based group and assists to maintain opportunities for social connection throughout the year. Attendance at these and similar social events reinforces the existence of the social networks underpinning community engagement. By contrast, a negative 'tight' feedback loop may be created by the dominance of a member, or members, who act as gatekeeper(s) of knowledge, excluding locals who are newcomers or in non-LC organizations. Such practices may predispose others in the groups to "relational lock-in," which creates obligations and norms that constrain people's ability to participate, innovate, and contribute (Maurer and Ebers 2006). Members may drop out of the network or place themselves on the periphery as a consequence of disempowerment or disengagement with the group's interests. In LGA, for example, the small active membership has focused on linking their town's urban space to the wider agricultural landscape beyond. The focus on restoration of indigenous vegetation in a park has allegedly contributed to the disengagement of farmers from LGA.

It obviously came across that the farmers [who attended a focus group session] were disgruntled. But there were only two of them there out of the group. The rest of them were all sort of urban. And I thought, the group doesn't work at its best but that might be because of the conflict of interest ... the farmers don't go to the townies and the townies don't go to the farmers ... there aren't the people to go to the things the farmers want them to go to. The farmers have dropped out of this group. They're not interested anymore because it's urban [a township of approximately 1000 people] (SNA participant [9], follow-up interview 2009).

The impact of such disconnection on LGA's NRM networks could include a loss of agricultural producers' land management knowledge, diminishing the breadth of local knowledge held within LGA's NRM networks. One executive member from LGA also recognized that the group no longer holds the skill set to fulfill the land management needs of primary producers, and this could have consequences in terms of regional landscape management in the event of bush or grass fires.

The network maps created awareness of connectivity between LC members. It also highlighted disconnections and identified opportunities for making changes to the way the group was functioning. In this way, the network maps serve as direct feedback loops creating a space for reflection and review of network management priorities. Two opportunities were 
recognized: first that the group could broaden their membership base because more connections would strengthen their information networks; and second that more members needed to become involved in the core activities of the group to share the workload and to leverage the value of all members' skill sets and contacts. The opportunity to reflect on the network maps gave participants opportunities to think strategically about the future of their groups:

The group needs to widen their embrace and recruit new members. The group needs to build up their network more and involve more people, both within their current membership and by recruiting new members (SNA participant [11], follow-up interview 2009).

The group needs to spread the base of significant leadership and expertise more widely. The group needs to delegate and train people, in a nonthreatening way, to give other members the experience of leadership (SNA participant [16], follow-up interview 2009).

\section{Redundancy}

Redundancy refers to the resources available to a network that prevent it from fragmenting if certain nodes or members leave. Further, a resilient LC network will have high redundancy if its members are capable of sharing roles so it is not dependent on any single person.

To consider the implications of key executive members leaving LGA and LGB 'what-if' scenarios were undertaken in which key executive members of each group were theoretically removed from the networks. Figures 11 and 12 indicate that each network would begin to fragment if at least three executive members or key network people were unable to continue, to contribute, or if they left the group at the same time.

Fig. 11. Fragmentation of Landcare Group A based on 'what-if' scenario.

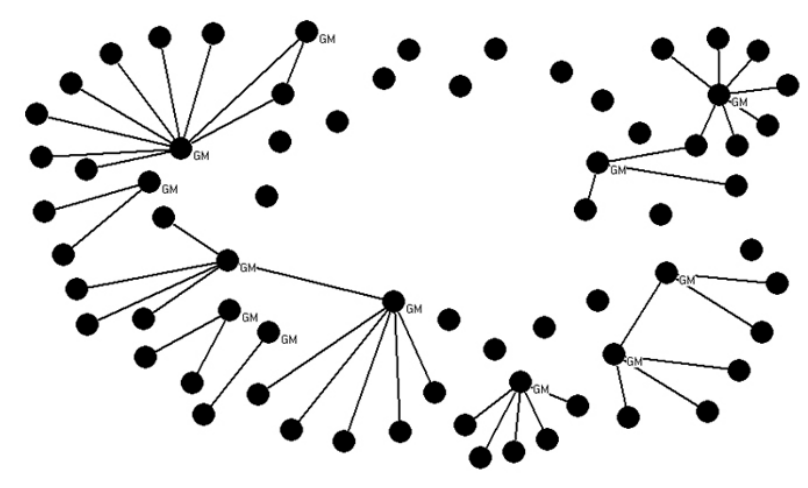

Fig. 12. Fragmentation of Landcare Group B based on 'what-if' scenario.

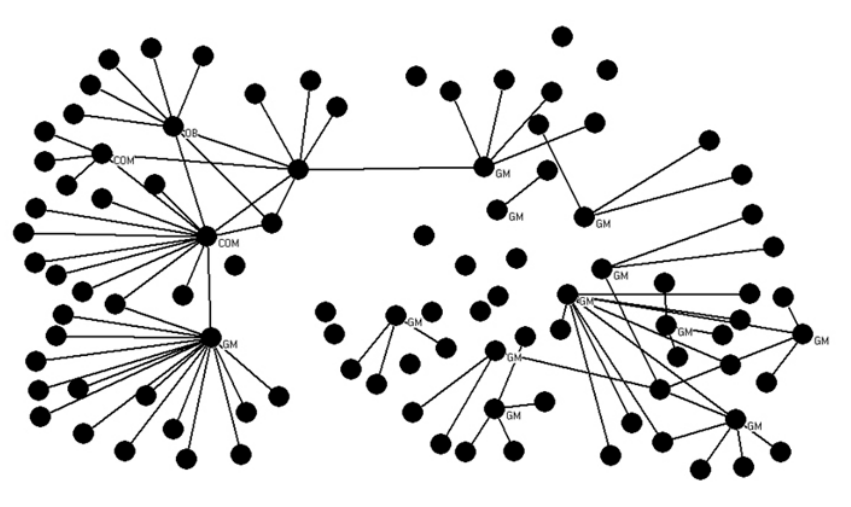

The remaining individuals and cluster still retain their NRM contacts for information, but internal communication and connectivity between LC members is diminished significantly. LGB made sense of this hypothetical situation (Fig. 12) by recognizing the potential vulnerability, but observed that in their previous experience, and in such a scenario, other members would come forward to step into vacant executive roles and ensure the group remained a functional and cohesive group. This explanation of group dynamics indicates agency among group members, and as Garguilio and Benassi (2000) note, it is this ability of individuals to consciously play a role in the network evolution that is important to actors, especially because actors are usually described as being constrained by their networks. The exercise of theoretically fragmenting the network was important to enable the group to prioritize succession as an issue for their discussion. In addition, the network snapshot provided a visual representation of the importance of particular roles or people in the group. This stimulated reflection during feedback sessions about the importance of deliberately sustaining connectedness of the group both internally and externally.

The group is heavily reliant on a few key people and if those key people aren't there then you've either got to replace them or the whole thing can fall in a heap (SNA participant [1], follow-up interview 2009).

The study revealed that [LGA's] network is vulnerable, that it is too reliant on a core group of people to do the work (SNA participant [11], followup interview 2009).

Although it would be expected that internal connectivity would be centered on certain members who are either selfappointed or in official roles to keep the membership informed about LC issues, in both LGA and LGB it was appreciated that greater redundancy was needed to ensure that a wider range 
of members would be available and willing to provide leadership, and therefore reduce the risk of group fragmentation along with loss of critical capability. In other words, the groups appreciated that they were maintaining significant LEK and this experience was central to their purpose as groups.

Overall, the empirical findings make the previously invisible network activities of community LCs visible, thus revealing the rich social fabric that links peri-urban residents together in apparently disconnected, in terms of NRM practices, transitional landscapes. In particular, the SNA tool was useful in demonstrating the resilience aspects of diversity and redundancy. The pilot was a useful learning process to identify the strengths and limitations of the methodology for both the research team and the LC community.

\section{DISCUSSION}

\section{Social network analysis as a visual mapping tool that is useful to Landcare networks}

The pilot study indicated that the groups found the analyzed data useful in facilitating dialogue within their group, especially with regard to organizational management and structure:

I think that it does put a sharp focus on things like succession and things like where the leadership's coming from, where the expertise is coming from, and raising that awareness of the need to spread it more widely (SNA participant [16], follow-up interview 2009).

The SNA tool catalyzed reflection opportunities and acted to reinforce intuitive understanding of the social networks, or to inform previously unobserved instances of local connections or the paucity of such links. From the community engagement team perspective, it provided direction for investment, in particular indicating where extension support would be most useful. It also provided the DSE team with a tool that helped to show the complex information networks that operate through social connectivity within the regions. Although our findings indicate that the sociograms provide a visual mapping of the communities' engagement with particular NRM activities, the management of the tool itself was too complex for local groups, and agency personnel were unable to add this task to their job descriptions because their numbers have dwindled and time pressures have increased for the few remaining coordinators. The efficacy of this SNA tool therefore relies on the input of skilled agency personnel or research partners, particularly in accessing the software and facilitating the interpretation process of the sociograms. Regardless of these practical limitations, the capacity to demonstrate how these networks organize and adapt underpins local groups' and government's ability to respond to landscape change. Monitoring social resilience in this way can provide early warning of a breakdown in the network compromising its function and indicates responses to policy initiatives. As a result of our analysis of this pilot study and in discussion with the participating LC group, facilitators, and agency personnel engaged with LC, we reflected on our earlier descriptions of what each of Walker and Salt's (2006) qualities of resilience meant in the LC context. We also considered the implications of each of these in the context of policy associated with funding CBNRM for social resilience outcomes.

\section{Diversity}

The maps indicated a higher level of diversity of interests and contacts between both groups than might have been expected historically in rural, regional, and now peri-urban landscapes. The multiple interests that cause people to participate means that for most LC members CBNRM outcomes are no longer based in having farming, for example, as a common bond. Instead, the common thread is the gaining of LEK and both groups demonstrated an inclusivity that encourages community to attend. Neither group had sustained engagement with those still farming in these regions, but because we did not interview nonmembers, we can only hypothesize why farmers were mostly absent from the sample. We define farmers here as those who earn the largest percentage of annual income from their farm. The diversity of interest, experience, and willingness to network for information and to share it suggests a high degree of social cohesion in both groups. This is likely to contribute to their social resilience as a community in this location. Prell et al. (2011) also noted the importance of diversity of stakeholders in determining the structure of the network, and our study indicates the diversity of networks available to the groups. Non-LC members are also connected to the LC network structure through the shadow networks of other community organizations, and in reality, the limited pool of people in the region ensures a certain cross fertilization of ideas through general contact, for example, at the post office, on the side of the road, and at other community gatherings.

\section{Modularity}

Modularity as displayed in Figures 5-10 indicates that members demonstrate some flexibility in communicating or responding to NRM issues, in that contacts were both internal and external to the LC organization. Communication was with neighbors, family, friends, service providers, and government agencies located locally and nonlocally. Further, the clustering around different NRM issues in both these pilot groups highlights the diversity of organizational objectives culminating in emerging and opportunistic relations, i.e., shadow networks (Wenger 1998, Shaw 2002) and provides a clear reason for the import of modularity as found in LC network NRM communication. This inherent, opportunistic, or cultivated adaptability suggests that the overall functioning of the group relies on a sense that individual members are trustworthy sources of information, or have reliable connections to outside sources. As Scoones (as cited in 
Colding et al. 2003) notes, local scale may be the most adaptable to local opportunities. Emergent pathways were shared within the group, for example, when one group decided to link with the local country firefighting network (CFA) to cross-reference decisions within the group about appropriate places to revegetate along roadsides. The CFA members, contacted in this informal way, allowed the LC group to access their volunteer fire members' network thus creating a shadow network for $\mathrm{LC}$ and providing additional information for their LC group decision making. In other words, this created the potential to nurture innovative ideas through spontaneous knowledge exchanges that occurred outside the dominant structures (Westley et al. 2011), in this case the conventional NRM governance system. We can also situate these specialist committees and NRM issue-based clusters as a part of a larger, multiscalar LC group network and as elements of a CBNRM system while still operating relatively independently of other LC groups. These probably belong to a physical place in the landscape, but could also be virtual online communities (Wilson 2004) operating as region-based Landcare networks, contributing to national Landcare, and in effect operationalizing multiscalar defined modularity in the larger CBNRM system. We note that there is flexibility within local LC network structures to scale up, encompassing subregional groups, i.e., Landcare networks, (see Sobels et al. 2001 for an analysis of Landcare networks) and coordinating group activity across a subcatchment, as evidenced by LCB coordinating revegetation projects across local government jurisdictions.

Therefore, network-based modules can be understood as multiscalar networks comprising all CBNRM groups sharing LEK and administrative know-how at conferences, or with subcatchment networks contributing to regional CMAs or local government strategies for sustainable landscape management. If we think about the connectivity between LC groups as modules of a statewide LC network, then there is also high modularity across this state-scale network. Loss or change in LGA, for example, is unlikely to affect LGB.

\section{Redundancy}

Redundancy is generally about the function of the network, and within LGA, there were dramatic internal differences of opinion described to us in the interviews that indicated a degree of diversity of information flow. This is not to be interpreted as divisive or wholly negative because it could also contribute to better decision making because there are multiple voices describing 'same but different' ways of acting and assembling knowledge. These voices are also the backup should a voice, and its LEK, be lost to the group. In this way the quality of redundancy is present in both groups, but because their membership is relatively small, they appear to specialize/ diversify into subcommittees or projects to accomplish all the needs of the groups. The interview response of LGA that if a committee member left, another member would step up to do the task, a situation not shown in the sociogram, demonstrated the surety that the group has about its social coherence and, consequently, its social resilience.

\section{Feedback}

Feedback within each network was different at different scales. The decline in national funding for local facilitators, rather than the regional facilitators with which we originally scoped the project, increased the uncertainty that both groups discussed around the value of their on-ground works to the nation. Note that they were very clear about the value they personally placed on the work they were doing, unsurprisingly, given LC's voluntary nature. This apparent isolation from the national purpose, however, seemed to suggest a social resistance that in different situations could transform to either negative or positive outcomes. In the short term, at a local scale, local resilience, as in maintaining their LC and CBNRM activities, appeared to translate into a coherent community response to seek and provide each other with relevant information and opportunities for local funding through local industry and regional water authorities.

\section{Potential implications for natural resource management policy from the social network analysis pilot study}

Diversity

Diversity as an indicator of the quality of the social resilience in the LC group is represented in the SNA maps, even at this most rudimentary level. SNA makes visible the social mosaic within the landscape. It indicates the relationships are not predetermined or fixed. Evidence of diversity suggests more opportunity for action and greater knowledge flow. One comment from a state agency community engagement and Landcare officer during the 2009 analysis process was that recognition of the diversity of people, interests, and information sources meant that previous models of information dispersal with a 'one message fits all' approach were outdated. The reality of the landscape as a site for increasing conservation and biodiversity values also means there is a need for more support for LEK and emphasizes the possibility of a decentralization of knowledge generation sources for CBNRM practices.

\section{Modularity}

Modularity at a local scale, which is reinforced by internal information flows and adaptive capacity, is evidenced here. However, there is still a need for a larger landscape scale strategic direction to provide some overall aggregation of best practice. This also assists in promoting adaptive best practice and responsible land stewardship. Within LC networks, diversity of groups across the landscape ensures that LEK, although potentially having an impact on and reflecting a connected ecosystem, can also demonstrate diversity of local knowledge. In this way, a high degree of modularity means there is room for individual groups to develop particular 
practices based on local innovation and conditions. The possible uptake of these by other LC groups or networks can allow for adaptation of practices rather than imitation contributing to the diffusion of knowledge and adding to placebased social memory (Westley et al. 2011). Overall, this strengthens the network quality and values different experiential learning.

\section{Redundancy}

Redundancy is the quality that stands out in this study as largely unrecognized as an important characteristic of CBNRM in the landscape. The initial paradox arose from the beginning of the LC's "Decade of LC," declared in 1989 by then Prime Minister Bob Hawke. The rhetoric was of local solutions to local problems, and although this reinforced the idea of LEK in place, government at state and national scale moved very quickly to organize LC groups into larger networks and aggregated funding bids, for ease of administration and strategic conservation values. The tension is now reversed because government at both scales decreases funding support, and local LC and other CBNRM groups turn inwards to consolidate, as well as outwards to seek advice elsewhere. In effect, because communities are already under a lot of pressure from declining agricultural markets, diminished infrastructure and opportunities in small regional and rural centers, LEK becomes part of a more general consolidation of knowledge, adaptive capacity, and resilience. Recent experiences with regard to drought and energy policy among farming communities in Victoria (Beilin et al. 2012) indicate that different policy tools do not necessarily complement each other, but rather tend to invade the same space creating the likelihood of perverse outcomes and ignoring or misunderstanding the social systems that exist in the landscape. Market-based incentives (MBIs) are an example of a national policy tool that undermines local LC activity by targeting private funding of ecological change outcomes in the same communities in which there are active CBNRM programs. Further, as Ernstson (2011) notes, transformative, collective action requires that at a most basic level the actors in their networks relate to each other through information exchange and consolidate their learning as they go, even if or even when it challenges accepted ways of doing things. The LC networks analyzed here are the survivors of various 'shocks' associated with the inability of the state, federal and provincial, to maintain support staff or guaranteed funding levels for CBNRM. Nonetheless, it is our understanding that although these conditions are lamentable, it has not as yet diminished local function. Therefore, redundancy within the groups was important to maintain LEK and group function, and redundancy across the LC network and CBNRM system was important to assure on ground action in the face of dynamic social and economic conditions at various scales.

\section{Feedback}

Feedback affects all parts of the network and the scale of their effect is determined by the interaction of, in this case, the actors and objects within the LC and CBNRM system. At a policy level, moderating the impact of the feedback loop may be critical to maintaining, managing, or abandoning the network (s). Policy that supports positive feedback may be that which assists in prompt funding during difficult circumstances, such as providing LC grants for community plantings in areas of flood or other landscape scale disasters. Similar to the Depression in America and Australia in the 1920s, work on public lands and public good may provide much needed social and economic support and have clear ecological benefit. Respondents in this study had no trouble describing negative feedback loops, such as government policies that neglected the importance of CBNRM in facilitating social and ecological literacy. They argued that such literacy contributed to building adaptive capacity. We argue that literacy and capacity underpin social resilience in regional landscape management.

\section{CONCLUSIONS}

Community based natural resource management and programs like LC contribute to the social resilience of their communities. Landcare demonstrates an effective communication of the cultural expectations and practices inherited over 25 years of LC activity in Victoria. They are adaptive, engaged, highly diversified, connected to their new landscapes, and invest socially and economically in keeping their LC networks alive.

We asked if a tool like SNA would be useful to LC groups in helping them to understand and evaluate how their networks functioned, and at a very simple level, given the simple displays that we provided, the answer was yes. Both groups in the pilot study found that they reflected on their activities and on the structure as a consequence of having the SNA displays presented to them and discussed. We found that the processing of the data for the groups raised several issues that we had not anticipated. First, there was an ethical concern voiced by community members and by the researchers that if the local group ran the process itself, some individuals would not want to participate because they would be identified by other locals. Second, the interrogation of data and interpretation requires training, and input is repetitive and needs to be carefully done. State level agency personnel were willing to be trained to undertake this task, but during the life of the project, steady cutbacks in their personnel and subsequent time constraints on those remaining precluded this from occurring.

We asked if SNA made the social structures and community capacity underpinning social and ecological resilience within these LC landscapes visible, with the intention that policy makers could more readily support such CBNRM networks if the connection between social networks and LEK was made 
more transparent. The agency personnel with whom we worked, and those attending the final presentation of the study to state government, were excited about the possibilities that this tool represents for both quantitative and qualitative interrogation because this has been a much neglected area.

Finally, we note that if transformative change in ecosystembased management (Ernstson 2011) is a societal goal, and we concur that it is critical, then the transitions to such transformation are central to advancing this objective. We present this use of SNA in a multiscalar landscape as one way of making visible these spaces and places of transition.

Responses to this article can be read online at: http://www.ecologyandsociety.org/issues/responses. php/5360

\section{Acknowledgments:}

We wish thank the Victorian Department of Sustainability and Environment for providing the funding for this 1.5 year project, our colleagues in the Department of Sustainability and Environment for their frank and enthusiastic collaboration throughout the research process, the SNA expertise of Barbara King was central to the formal SNA methodology, many invaluable insights and much guidance were contributed during this time, and we also wish to thank Albert Llausas for being a reliable sounding board during crucial rewriting stages. Finally, we are very grateful to all the Landcare group participants and key interviewees who gave their time, patience, and intelligence to the project.

\section{LITERATURE CITED}

Adger, W. N. 2003. Social capital, collective action, and adaptation to climate change. Economic Geography 79:387-404. http://dx.doi.org/10.1111/j.1944-8287.2003.tb00220. $\underline{x}$

Alexander, H. 1995. A framework for change: the state of the community landcare movement in Australia. National Landcare Facilitator Project, Canberra, Australia.

Altieri, M. A., Funes-Monzote, F. R., and Petersen, P. 2012. Agroecologically efficient agricultural systems for smallholder farmers: contributions to food sovereignty. Agronomy for Sustainable Development 32:1-13. http://dx.doi.org/10.1007/ s13593-011-0065-6

Andersson, K. P., and E. Ostrom. 2008. Analyzing decentralized resource regimes from a polycentric perspective. Policy Sciences 41(1):71-93. http://dx.doi. org/10.1007/s11077-007-9055-6
Australian Government. 2012. Landcare. Department of Agriculture, Fisheries and Forestry, Australian Government, Canberra, Australia. [online] URL: http://www.daff.gov.au/ natural-resources/landcare

Beilin, R. 1999. Looking for landcare: the landscape and the family farm. Dissertation. Royal Melbourne Institute of Technology (RMIT) University, Melbourne, Australia.

Beilin, R., and N. Reichelt. 2010. Community landcare: a key player in building social-ecological resilience networks? Discussion Paper, 2009. Victorian Government Department of Sustainability and Environment, East Melbourne, Australia. [online] URL: http://svc009.wic050p.server-web.com/wpcontent/uploads/2010/09/DSEreport2009.pdf

Beilin, R., T. Sysak, and S. Hill. 2012. Farmers and perverse outcomes: the quest for food and energy security, emissions reduction and climate adaptation. Global Environmental Change 22:463-471. http://dx.doi.org/10.1016/j. gloenvcha.2011.12.003

Bodin, Ö., and B. Crona. 2009. The role of social networks in natural resource governance: what relational patterns make a difference? Global Environmental Change 19:366-374. http:// dx.doi.org/10.1016/j.gloenvcha.2009.05.002

Bodin, Ö., B. Crona, and H. Ernstson. 2006. Social networks in natural resource management: what is there to learn from a structural perspective? Ecology and Society 11(2): r2. [online] URL: http://www.ecologyandsociety.org/vol11/iss2/resp2/

Burel, F., and J. Baudry. 2003. Landscape ecology: concepts, methods and applications. Science, Plymouth, New Hampshire, USA.

Campbell, A. 1994. Landcare: communities shaping the land and the future. Allen and Unwin, Sydney, Australia.

Carr, A. 2002. Grass roots and green tape: principles and practices of environmental stewardship. Federation, Annandale, New South Whales, Australia.

Colding, J., T. Elmqvist, and P. Olsson. 2003. Living with disturbance: building resilience in social-ecological systems. Pages 163-187 in F. Berkes, J. Colding, and C. Folke, editors. Navigating social-ecological systems: building resilience for complexity and change. Cambridge University Press, Cambridge, UK.

Crona B., and Ö. Bodin. 2010. Power asymmetries in smallscale fisheries: a barrier to governance transformability? Ecology and Society 15(4): 32 [online] URL: http://www. ecologyandsociety.org/vol15/iss4/art32/

Curtis, A., D. Lucas, M. Nurse, and M. Skeen. 2008. Achieving NRM outcomes through voluntary action: lessons from landcare - Discussion Paper. Victorian Government Department of Sustainability and Environment, Melbourne, 
Australia. [online] URL: http://www.dse.vic.gov.au/ data/ assets/pdf file/0003/102279/DSE005 Discussion Paper Web low res.pdf

Curtis, A., and R. Sample. 2010. CBNRM in Victoria: contributing to dialogue, learning and action. A report to the Victorian Department of Sustainability and Environment. Institute for Land, Water and Society, Charles Sturt University, Albury, New South Whales, Australia. [online] URL: http://athene.riv.csu.edu.au/ acurtis/reports/ CBNRM_Victoria_Final_Report_July.pdf

De Nooy, W., A. Mrvar, and V. Batagelj. 2005. Exploratory social network analysis with Pajek. Cambridge University Press, Cambridge, UK.

Ernstson, H. 2008. In Rhizomia: actors, networks and resilience in urban landscapes. Dissertation. Stockholm University, Stockholm, Sweden.

Ernstson, H. 2011. Transformative collective action: a network approach to transformative change in ecosystembased management. Pages 255-287 in Ö. Bodin and C. Prell, editors. Social networks and natural resource management: uncovering the social fabric of environmental governance. Cambridge University Press, Cambridge, UK.

Ewing, S. A. 1995. It's in your hands: an assessment of the Australian landcare movement. Dissertation. University of Melbourne, Melbourne, Australia.

Folke, C. 2006. Resilience: the emergence of a perspective for social-ecological systems analyses. Global Environmental Change 16:253-267. http://dx.doi.org/10.1016/j.

gloenvcha.2006.04.002

Harris, G. 2007. Seeking sustainability in an age of complexity. Cambridge University Press, Cambridge, UK.

Holling, C. S., and G. K. Meffe. 1996. Command and control and the pathology of natural resource management. Conservation Biology 10(2):328-337. http://dx.doi.org/10.1046/ j.1523-1739.1996.10020328.x

Janssen, M. A., and E. E. Osnas. 2005. Adaptive capacity of social-ecological systems: lessons from immune systems. EcoHealth 2:93-101. http://dx.doi.org/10.1007/s10393-004-0158-7

Johnson, S. 2001. Emergence. Penguin, New York, New York, USA.

Landcare Australia. 2012. The National Landcare Facilitator Project. Landcare Australia, Sydney, Australia. [online] URL: http://www.landcareonline.com.au/?page $\mathrm{id}=1477$

Lawrence, G. 1987. Capitalism and the countryside: the rural crisis in Australia. Pluto, London, UK.

Lawrence, G. 1995. Futures for rural Australia: from agricultural productivism to community sustainability.
Central Queensland University, Rockhampton, Queensland, Australia.

Lobao, L., and K. Meyer. 2001. The great agricultural transition: crisis, change, and social consequences of twentieth century US farming. Annual Review of Sociology 27:103-124. http://dx.doi.org/10.1146/annurev.soc.27.1.103

Marín, A., and F. Berkes. 2010. Network approach for understanding small-scale fisheries governance: the case of the Chilean coastal co-management system. Marine Policy 34:851-858. http://dx.doi.org/10.1016/j.marpol.2010.01.007

Maurer, I., and M. Ebers. 2006. Dynamics of social capital and their performance implications: lessons from biotechnology startups. Administrative Science Quarterly 51 (2):262-292. http://dx.doi.org/10.2189/asqu.51.2.262

Meinig, D. W. 1979. The interpretation of ordinary landscapes: geographical essays. Oxford University Press, Oxford, UK.

Ostrom, E. 1999. Coping with the tragedy of the commons. Annual Review of Political Science 2:493-535. http://dx.doi. org/10.1146/annurev.polisci.2.1.493

Prell, C., M. Reed, and K. Hubacek. 2011. Social network analysis for stakeholder selection and the links to social learning and adaptive co-management. Pages 95-118 in Ö. Bodin and C. Prell, editors. Social networks and natural resource management: uncovering the social fabric of environmental governance. Cambridge University Press, Cambridge, UK.

Relph, E. C. 1976. Place and placelessness. Pion, London, UK.

Robins, L., and P. Kanowski. 2011. 'Crying for our country': eight ways in which 'caring for our country' has undermined Australia's regional model for natural resource management. Australasian Journal of Environmental Management 18 (2):88-108. http://dx.doi.org/10.1080/14486563.2011.566158

Samuels, M. S. 1979. The biography of landscape. Pages 51-88 in D. Meinig, editor. The interpretation of ordinary landscapes: geographical essays. Oxford University Press, Oxford, UK.

Shaw, P. 2002. Changing conversations in organizations: a complexity approach to change. Routledge, London, UK.

Simon, F., and A. Tellier. 2011. How do actors shape social networks during the process of new product development? European Management Journal 29(5):414-430 http://dx.doi. org/10.1016/j.emj.2011.05.001

Simpson, G., and J. Clifton. 2010. Funding and facilitation: implications of changing government policy for the future of voluntary landcare groups in Western Australia. Australian 
Geographer 41(3):403-423. http://dx.doi.org/10.1080/00049182.2010.498043

Sobels, J., A. Curtis, and S. Lockie. 2001. The role of landcare group networks in rural Australia: exploring the contribution of social capital. Journal of Rural Studies 17:265-276. http:// dx.doi.org/10.1016/S0743-0167(01)00003-1

The State of Victoria. 2008. Victoria 2008 state of the environment summary: living well within our environment. Are we? Can we? Commissioner for Environmental Sustainability, Victoria, Melbourne, Australia.

The State of Victoria, Department of Sustainability and Environment. 2010. Victorian landcare report card 2008/2009.Victorian Government Department of Sustainability and Environment, Melbourne, Australia. [online] URL: http:// www.landcarevic.net.au/news/2008-2009-victorian-landcarereport-card

The State of Victoria, Department of Sustainability and Environment. 2012. Land management: Victorian landcare program strategic plan. [online] URL: http://www.dse.vic. gov.au/land-management/land/landcare/victorian-landcare-programstrategic-plan

Stedman, R. C. 2003. Is it really just a social construction? The contribution of the physical environment to sense of place. Society and Natural Resources 16:671-685. http://dx.doi. org/10.1080/08941920309189

Stein, C., H. Ernstson, and J. Barron. 2011. A social network approach to analyzing water governance: the case of the Mkindo catchment, Tanzania. Physics and Chemistry of the Earth, Parts A/B/C 36(14-15):1085-1092. http://dx.doi. org/10.1016/j.pce.2011.07.083

Taylor, P. D., L. Fahrig, and K. A. With. 2006. Landscape connectivity: a return to basics. Pages $29-43$ in K. R. Crooks and M. Sanjayan, editors. Connectivity conservation. Cambridge University Press, Cambridge, UK.

Walker, B., and D. Salt. 2006. Resilience thinking: sustaining ecosystems and people in a changing world. Island, Washington, D.C., USA.

Wenger, E. 1998. Communities of practice: learning, meaning, and identity. Cambridge University Press, Cambridge, UK.

Westley, F., P. Olsson, C. Folke, T. Homer-Dixon, H. Vredenburg, D. Loorbach, J. Thompson, M. Nilsson, E. Lambin, J. Sendzimir, B. Banerjee, V. Galaz, and S. van der Leeuw. 2011. Tipping toward sustainability: emerging pathways of transformation. AMBIO 40(7):762-780. http://dx. doi.org/10.1007/s13280-011-0186-9
Williams, R. 1990. Between country and city. Pages 2-18 in S. Pugh, edior. Reading landscape: country-city-capital. Second edition. Manchester University Press, Manchester, UK.

Wilson, G. A. 2004. The Australian landcare movement: towards 'post-productivist' rural governance? Journal of Rural Studies 20(4):461-484 http://dx.doi.org/10.1016/j. jrurstud.2004.03.002

Yamaguchi, K. 1994. The flow of information through social networks: diagonal-free measures of inefficiency and the structural determinants of inefficiency. Social Networks 16:57-86. http://dx.doi.org/10.1016/0378-8733(94)90011-6 